\title{
ADAR1: "Editor-in-Chief" of Cytoplasmic Innate Immunity
}

\author{
Mart M. Lamers, Bernadette G. van den Hoogen and Bart L. Haagmans*
}

Department of Viroscience, Erasmus MC, Rotterdam, Netherlands

Specialized receptors that recognize molecular patterns such as double stranded RNA duplexes - indicative of viral replication-are potent triggers of the innate immune system. Although their activation is beneficial during viral infection, RNA transcribed from endogenous mobile genetic elements may also act as ligands potentially causing autoimmunity. Recent advances indicate that the adenosine deaminase ADAR1 through RNA editing is involved in dampening the canonical antiviral RIG-I-like receptor-, PKR-, and OAS-RNAse $L$ pathways to prevent autoimmunity. However, this inhibitory effect must be overcome during viral infections. In this review we discuss ADAR1's critical role in balancing immune activation and self-tolerance.

Keywords: ADAR1, cytoplasmic innate immunity, PKR, MDA5, OAS, RIG-I

\section{OPEN ACCESS}

Edited by:

Timothy B. Niewold,

New York University School of

Medicine, United States

Reviewed by:

Taruna Madan,

National Institute for Research in

Reproductive Health (ICMR), India

Surya Pandey,

University of Chicago, United States

*Correspondence:

Bart L. Haagmans

b.haagmans@erasmusmc.n

Specialty section:

This article was submitted to Molecular Innate Immunity,

a section of the journal

Frontiers in Immunology

Received: 06 February 2019 Accepted: 11 July 2019 Published: 25 July 2019

Citation:

Lamers MM, van den Hoogen BG and

Haagmans BL (2019) ADAR1:

"Editor-in-Chief" of Cytoplasmic Innate

Immunity. Front. Immunol. 10:1763.

doi: 10.3389/fimmu.2019.01763

\section{INTRODUCTION}

Our innate immune system has evolved to specifically recognize common molecular patterns formed as a result of virus replication. These molecular patterns-commonly referred to as pathogen-associated molecular patterns or PAMPs-are detected by specialized receptors, called pattern recognition receptors (PRRs), which can rapidly trigger the immune system after ligand recognition. The replication of virtually all RNA viruses and even dsDNA viruses generates long, perfectly base-pairing double stranded (ds) RNA intermediates in the cytoplasm. As these dsRNAs are unusual in the cytoplasm of eukaryotic cells, sensory systems have evolved to detect this PAMP. These systems then signal the presence of an invading virus, allowing the cell to take appropriate measures. The main system detecting cytoplasmic dsRNA is the RIG-I-like receptor (RLR) signaling pathway, named after the first cytoplasmic PRR discovered: retinoic acid-inducible gene I $(1,2)$ (RIG-I). Subsequently, another related protein, melanoma differentiation-associated gene 5 (MDA5), was also found to be involved in dsRNA sensing (3). RLR signaling results in the production of the antiviral type I interferons (IFN) after PRRs oligomerize along dsRNA filaments. These oligimerized PRRs recruit the scaffolding protein mitochondrial activation signaling (MAVS) and IKK-related kinases and this ultimately results in the phosphorylation of the transcription factors interferon regulatory factor 3 and 7 (IRF3 and IRF7) $(4,5)$. These transcription factors then move to the nucleus where they activate type I IFN promoters leading to the secretion of IFNs (6). Next, IFN receptor signaling leads to the induction of an antiviral state in the producing and neighboring cells through the upregulation of interferon stimulated genes (ISGs), which encode proteins with direct antiviral effector functions, such as protein kinase R (PKR), $2^{\prime}-5^{\prime}$-oligoadenylate synthetase 1 (OAS1), and RNAse L.

While PRR activation and IFN production are tightly controlled in order to prevent false triggering of the immune system, it is becoming clear that certain endogenous RNAs can also form dsRNAs. This includes RNAs transcribed from retrotransposons, such as Alu repeats, and RNAs originating from the mitochondrial matrix (7). Although these RNAs have the correct structure to activate PRRs, they appear not to do so under normal circumstances as this would lead to 
severe autoimmune disease (8). This raises the question as to how cells distinguish between self and non-self nucleic acids.

One process that may be involved in the discrimination between self and non-self nucleic acids is the editing of RNAs. RNA editing is a process that regulates and expands the diverse functions of RNA transcripts and several types of editing have been characterized so far. In mammals, two forms of RNA editing exist, the deamination of cytosines to uracils by members of the apolipoprotein B mRNA editing enzyme catalytic subunit (APOBEC) protein family, and the deamination of adenosines to inosines (A-to-I editing) by the adenosine deaminase acting on RNA (ADAR) gene family. The cell's translation and splicing machineries interpret inosines as guanosines, instead of the adenosines encoded in the genome (9). This can lead to non-synonymous substitutions if editing takes place in coding sequences (10). More importantly, A-to-I substitutions have the capacity to destabilize dsRNA structures formed between complementary strands due to the replacement of Watson-Crick AU base pairs by IU wobble pairs, which are isomorphic with $\mathrm{GU}$ base pairs (11).

Mounting evidence suggests that cytoplasmic antiviral immunity is controlled at the level of dsRNA recognition by RNA editing, which appears to play a pivotal role in maintaining self-tolerance and preventing autoimmunity. Intriguingly, mutations in the adenosine deaminase ADAR1 can confer autoimmunity in humans and in mice models (12-17) and recently ADAR1 has been shown to regulate the canonical RLR-, PKR-, and OAS-RNAse L pathways. This review summarizes recent advances related to the function of ADAR1 as a "master regulator" of cytoplasmic innate immunity and discusses how the host can still mount an effective antiviral response in the presence of ADAR1.

\section{ADAR1: RNA EDITOR INDUCED BY IFN}

A-to-I editing was originally discovered as enzymatic activity unwinding dsRNA in Xenopus laevis $(18,19)$. The protein responsible for this activity, now known as ADAR1, was termed an RNA unwindase, and shortly thereafter it was found to also possess A-to-I editing activity (20-24). In addition, two other ADARs were discovered, thus comprising a gene family of three members in mammalian genomes (10, 25-28). Two encode for ubiquitously expressed enzymes with adenosine deaminase activity, the IFN-inducible ADAR1 and the constitutively expressed ADAR2 $(24,29,30)$. The third, ADAR3, has not been shown to possess any enzymatic activity and is expressed primarily in the brain (30-32). ADAR proteins show extensive architectural similarity, with centrally located three repeated copies of a dsRNA-binding domain (dsRBD) and a single deaminase domain at the C-terminus (Figure 1). The presence of these dsRBDs underlines that ADAR activity is directed toward dsRNA.

ADAR1 is expressed to higher levels than the other ADARs and it is responsible for the majority of editing activity (30). The protein encoded by this gene exists in two forms that are generated from alternative exon 1 structures that initiate from

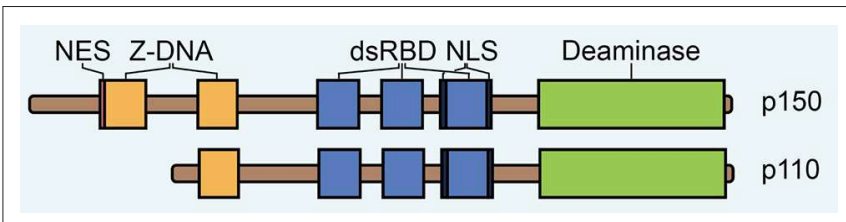

FIGURE 1 | The domain architecture of ADAR1 isoforms p150 and p110. NES, nuclear export signal; dsRBD, double-stranded RNA binding domain; NLS, nuclear localization signal.

different promoters (33). A small isoform (p110) is expressed constitutively while a larger isoform (p150) is upregulated in response to IFN. The p110 isoform is a truncated version of p150, lacking one Z-DNA binding domain at the N-terminus, which contains a nuclear export signal (NES) $(33,34)$ (Figure 1). Therefore, p110 is almost exclusively found in the nucleus while p150 is largely expressed in the cytoplasm (35-38). A bimodal nuclear localization signal (NLS) flanking the third dsRBD mediates nuclear import via transportin-1 (39).

\section{ADAR1 BLOCKS RIG-I-LIKE RECEPTOR SIGNALING}

The promoter responsible for p150 expression possesses a consensus interferon-stimulated response element (ISRE) characteristic of ISGs $(33,35,40)$. The discovery of this element promised an important role for ADAR1 in the immune response soon after the protein was discovered. The importance of ADAR1 for survival was already recognized early on as Adar1 $1^{-/-}$mice die by embryonic day 11.5-14 with widespread apoptosis and cell death of liver hemotopoietic cells (41-43). Clues to the mechanism underlying this lethality, however, could only be understood after the discovery of RLR signaling. In 2009, Hartner and colleagues found that the mortality in Adar ${ }^{-/}$embryonic mouse model was associated with the overexpression of IFN (44), and three studies in 2014-2015 showed that lethality can be rescued to live birth by deleting either Mavs or Mda5 as well $(13,15,16)$. In contrast, Rig-I deletion did not rescue lethality and inflammatory responses of $\mathrm{Adar}^{-/}$embryos (16). These findings indicated that in mice ADAR1 is able to block signaling through the MDA5-MAVS axis of the type I IFN signaling pathway, and that MDA5 is stimulated by endogenous dsRNA in ADAR1's absence. Knock-in of an editing-deficient form of ADAR1 did not rescue lethality, indicating that the enzymatic activity is crucial for survival (15). While Rig-I deletion in mice did not rescue embryonic lethality, several in vitro studies in mice and human cells have suggested that RIG-I activation is also blocked by ADAR1 (45-47). Notably, Yang et al. (45) described that the inhibitory effect of ADAR1 on RIG-I was mediated through RNA binding rather than editing activity. Differences in cell types, including HEK-293T cells, murine embryonic cells, macrophages, and hepatocytes may explain this discrepancy, as it is likely that the involvement of ADAR1 in RLR signaling is cell type dependent.

The discussed findings indicate that the dampening of RLR signaling is crucial to normal homeostasis and that 
endogenous RNA species can trigger RLRs in the absence of ADAR1. In agreement with the embryonic Adar ${ }^{-/}$mouse model, naturally occurring mutations in ADAR1 were found in humans with a severe and rare type I interferonopathy, termed Aicardi Goutieres syndrome (AGS) $(12,14)$. AGS is a fatal childhood encephalopathy characterized by uncontrolled IFN expression and IFN presence in cerebral spinal fluid, giving rise to symptoms reminiscent of a viral infection (48-51). Mutations in MDA5 have also been found in AGS patients $(52,53)$. These mutations were recently shown to enhance MDA5 activity by increasing its efficiency in recognizing dsRNA (54). A key question arose from this work: "What endogenous ligand is recognized by RLRs that triggers their activation in the absence of ADAR1 and viral replication?"

With the development of deep-sequencing this question could be addressed, for example by screening for editing sites globally. Such efforts showed that mobile genetic elements termed Alu repetitive elements, which can form dsRNA structures when transcribed as inverted Alu repeats, are the most frequent targets of A-to-I editing. Notably, Alu repeats are numerous: there are more than 1 million of these repeats present in the human genome, accounting for almost $11 \%$ of its size (55). Alu repeats are likely to be selectively edited due to their secondary structure and size, as ADAR1 editing does not require a strict consensus sequence [reviewed by: (56)]. A-to-I editing in Alu repeats disappears in ADAR1 knockout (KO) cells, possibly providing an unedited, immunostimulatory dsRNA substrate for RLR signaling $(54,57-71)$. Most of these Alu repeats are present in introns and $3^{\prime}$ untranslated regions (UTRs) of mRNAs and are transcribed by polymerase-II $(54,71)$. Mice do not possess the primate-specific Alu repeats, but it is conceivable that other mobile genetic elements capable of forming dsRNA, such as the closely related rodent B1-SINE, could stimulate MDA5 in similar ways if unedited. Additional substrates for ADAR1 editing may be mitochondrial dsRNAs (mtdsRNAs), as it was recently shown that patients with biallelic hypomorphic mutations in the PNPT1 gene, which encodes polynucleotide phosphorylase PNPase, contain mtdsRNAs in the cytoplasm that can activate MDA5 and induce IFN (7). Deep-sequencing of PNPase depleted cells revealed that mitochondrial RNAs were A-to-I edited. Concurrent depletion of PNPase and ADAR1 enhanced IFN expression, suggesting that ADAR1 editing of these endogenous RNAs blocks IFN activation. Editing of host dsRNAs could differentiate them from viral RNAs by altering their secondary structure to abrogate the formation of extended dsRNA duplexes, preventing IFN activation in uninfected cells (72). Alternatively, edited dsRNA could act as an active inhibitor of IFN signaling. Vitali et al. (73) found that extensively edited dsRNA (IUdsRNA) inhibits activation of the IFN pathway induced by the dsRNA mimic polyriboinosinic:polyribocytidylic acid (poly(I:C)) in vitro. As a mechanism the authors proposed that IU-dsRNA could bind to RLRs with higher affinity than poly(I:C), thereby preventing their activation. Mapping of A-to-I editing sites have shown that editing can be highly concentrated providing a source of the potential IFN-inhibitory IU-dsRNA in vivo (15). These data might indicate that ADAR1 is required to provide the cell with a ligand that actively inhibits IFN signaling (and possibly other cytoplasmic antiviral responses), a hypothesis that deserves continued investigation.

\section{ADAR1 BLOCKS PKR-INDUCED TRANSLATION ARREST}

A protein that is similar to ADAR1 in terms of its induction by IFN and presence of multiple dsRBDs, is the IFN inducible double-stranded RNA-activated protein kinase (PKR). PKR is one of the best-studied ISGs and its expression inhibits the replication of a wide range of viruses (74). It is also antagonized by several viruses, including influenza A virus, vaccinia virus and Ebola virus. It is a member of the eIF2 $\alpha$ family of protein kinases that also includes the PKR-like endoplasmic reticulum kinase (PERK), the general control nondepressible 2 kinase (GCN2) and the hemin-regulated inhibitor of translation (HRI). Each of these kinases is activated under different conditions of cellular stress, which is cytoplasmic dsRNA in the case of PKR. Substrate recognition leads dimerization via its dsRBDs $(75,76)$, autophosphorylation and subsequent phosphorylation of $\operatorname{eIF} 2 \alpha(77,78)$, which shuts down $5^{\prime}$-cap-dependent mRNA translation to prevent viral protein synthesis $(79,80)$. This is accompanied by the formation of cytoplasmic stress granules (SGs), dense aggregations of RNA and proteins that store stalled translation pre-initiation complexes.

Besides its function in dampening IFN induction, ADAR1 is also known to block translation arrest and stress granule formation by inhibiting PKR activation (81-86). Several studies have shown that ADAR1 functions in a proviral manner via RNA editing and inhibiting PKR. Examples include measles virus (MV) (83), vesicular stomatitis virus (VSV) (81, 85), and human immunodeficiency virus (HIV) $(82,87,88)$. In these cases, ADAR1 is able to block PKR and this inhibition was found to occur through both editing-dependent and independent mechanisms. For MV, ADAR1-deficiency was shown to lead to elevated cytotoxicity and apoptosis upon virus infection, while viral replication was decreased (83). Moreover, PKR activation observed in ADAR1 knockdown (KD) cells upon MV infection was not rescued by an editing deficient form of $\mathrm{p} 150$, indicating that for MV PKR inhibition is editing-dependent (89). In contrast, during VSV and HIV infection, ADARl's inhibitory effect on PKR was found to occur in an editing-independent fashion (81, 82). In the case of HIV, an increased interaction between ADAR1 and PKR was observed during infection, which could represent competition between both proteins for the same substrate, or could indicate that ADAR1 directly interacts with PKR to prevent its dimerization and subsequent autophosphorylation. Complex formation between ADAR1 and PKR is independent of RNA and the first dsRBD of ADAR1 is required for the binding (81). By interfering with the activation of PKR, ADAR1 prevents the phosphorylation of $\operatorname{IF} 2 \alpha$ and the formation of SGs, and consequently allows the translation of viral mRNAs $(81,83-85)$. 
The observation that Mavs and Adarl double knockout (DKO) mice still die shortly after birth suggests that the lethality of Adar1 $^{-/-}$mice is not solely reliant on IFN induction. Suppressing PKR may also be required for survival, even in the absence of viral infection. Interestingly, a recent study sheds more light on this (71). In this study, ADAR1 KO (either ADAR1 or ADAR1 p150) was shown to decrease protein, but not mRNA, levels of several ISGs following IFN treatment. This was associated with PKR and eIF2 $\alpha$ phosphorylation upon IFN treatment in KO, but not in wild-type (WT) cells. Furthermore, PKR KD in ADAR1 KO cells partially restored ISG protein levels, indicating that PKR activation in ADAR1 KO cells is responsible for the lack of ISG protein expression. Intriguingly, in IFN-treated ADAR1 KO cells, phosphorylated PKR levels were significantly reduced by transcription inhibition, suggesting that an endogenous RNA species, transcribed in response to IFN, is responsible for the activation of $\mathrm{PKR}$ in these cells. In this same study, it was found that $>90 \%$ of A-to-I editing takes place in Alu repeats, suggesting that ADAR1 editing or binding inhibits them from activating PKR. Altogether, these results indicate that ADAR1 is required for maintaining efficient translation during the IFN response and that endogenous RNA transcripts activate PKR in ADARl's absence. The endogenous RNA species that activate PKR could be the same RNAs that activate MDA5 in the absence of ADAR1, but this remains to be tested.

The relevance of the findings by Chung and colleagues was further underlined by generating ADAR1 KO human embryonic stem cells (hESC). While this genetic permutation was not lethal to these hESCs, they did exhibit spontaneous MDA5mediated IFN $\beta$ production, PKR activation, and apoptosis upon differentiation to neural progenitor cells (NPCs), indicating that requirements for ADAR1-mediated PKR or MDA5 inhibition depend on cell type or differentiation state. Also, the fact that NPCs are more vulnerable to the effects of ADAR1 deficiency may indicate why AGS is associated with neurological abnormalities. These results are in agreement with a study by Yang and colleagues, in which ADAR1 $\mathrm{KO}$ was induced in newborn mice. Upon sacrifice, these inducible ADAR1 KO mice showed high levels of IFN specifically in neuronal tissues (45). Unfortunately, neither studies showed whether the observed effects were PKR- or MDA5-mediated.

In agreement with the finding that SGs can function as platforms for RLR signaling (90), mounting evidence suggests that PKR is also involved in the induction of type I IFN (91). PKR may be involved in the activation of $\mathrm{NF}_{\kappa} \mathrm{B}$, a transcription factor required for efficient IFN induction, possibly through its interaction with the IKK complex (92). Moreover, PKR was shown to bind members of the TRAF family, which are involved in MAVS signaling (93). Further, several studies have shown that PKR is required for IFN production in response to poly(I:C) in vitro (94-97). PKR is also required for the production of type I IFN in response to a subset of viruses, including encephalomyocarditis virus, Theiler's murine encephalomyelitis virus, MV, West Nile virus, and Semliki forest virus, but not influenza and Sendai virus (98-102). In addition, a recent study showed that PKR interacts directly with MDA5 and is able to enhance MDA5-mediated IFN production (103).
Efficient IFN induction required the catalytic activity of PKR, but not the phosphorylation of eIF $2 \alpha$ suggesting that these effects are independent of the induction of SGs or translational shutdown. Although ADAR1 is able to inhibit PKR activation, the contribution of this inhibition to PKR-mediated type I IFN induction remains to be determined.

\section{ADAR1 BLOCKS THE OAS-RNASE L PATHWAY}

The IFN-inducible oligoadenylate synthetase (OAS)-RNase L pathway is activated upon sensing of dsRNA. OAS proteins (OAS1, OAS2, OAS3) produce 2',5'-oligoadenylates (2-5A) upon dsRNA recognition. This second messenger activates RNase $\mathrm{L}$ by binding with high affinity to the inactive, monomeric form of RNAse L, causing it to dimerize into its enzymatically active state (104). In this state it is able to cleave both viral and host ssRNA, predominantly after UpU and UpA dinucleotides, leaving a $5^{\prime} \mathrm{OH}$ and a $2^{\prime}, 3^{\prime}$-cyclic phosphate on the cleavage products (105). RNAse L activation can lead to translation arrest through cleavage of ribosomal RNA and mRNA $(79,106)$, autophagy $(107,108)$, and apoptosis (109-111), preventing viral replication, and spread.

A recent study reported that the cell-lethal phenotype of ADAR1 deletion in human lung adenocarcinoma A549 cells was rescued by RNASEL KO. This indicated that the OAS/RNase L pathway is the primary mechanism that leads to cell death in these cells, in the absence of ADAR 1 and even in the presence of MDA5 and MAVS (112). Furthermore, ectopic expression of active, but not inactive, RNase L, in ADAR1/RNASEL DKO cells promoted cell death, which supports the central role of RNase $\mathrm{L}$ activation in dsRNA-mediated cell death in this cell line. In addition, IFN-induced 2-5A accumulation was higher RNASELADAR1 DKO cells than in WT and RNASEL KO cells, indicating that ADAR1 prevents the activation of OAS. Moreover, these results suggest that ADAR1 is the primary regulator of RNAse $\mathrm{L}$ activation in this cell type, most likely by preventing OAS activation. Whether these data could be extrapolated to other cell lines or even the entire organism remains to be tested, but RNase L-mediated cell death in the absence of ADAR1 could potentially contribute to AGS. Furthermore, the findings in Adar and Mavs/Mda5 DKO mice and in ADAR1 KO NPCs suggest that not the OAS-RNAse L but the RLR signaling pathway leads to cell death in absence of ADAR1. Although it is uncertain at present which pathways downstream of RLR signaling are mediating lethality, these data indicate that the OAS-RNAse L pathway be an important mediator of cell death.

\section{ADAR1 AND VIRUSES}

A bias toward A-to-G and U-to-C mutations has been described for a wide range of genetically diverse viruses, suggestive of ADAR editing (113). This could potentially lead to the synthesis of dysfunctional viral proteins and RNA structures. Although several studies have reported high editing levels that suggest a mutagenic and antiviral role for ADAR1 (113), evidence of an 
important role for ADAR1 as part of the innate immune response against virus infections is lacking. Additionally, studies that have observed hypermutation have not yet shown, for example using genetic KOs, that a specific ADAR protein is responsible for editing, nor have they shown that editing itself leads to decreased virus replication. Furthermore, it must be noted that for many viruses it may not be possible to distinguish between the editing of replication-competent viruses and defective interfering (DI) viral genomes, which may be edited frequently (114-116). While editing of viral genomes could decrease infectivity, editing of DI viral genomes may prevent these from activating the innate immune system. Inhibition of ADAR editing has been reported for adenovirus and Vaccinia virus gene products, but it is yet unknown whether RNAs encoded by these DNA viruses are edited by ADARs. The adenovirus-associated (VAI) RNA is responsible for ADAR1 inhibition and interestingly it is also is capable of blocking both PKR and IFN induction (117-119). RNA binding by PKR is generally an activatory signal, but VAI RNA binding to PKR and ADAR1 is thought to sterically inhibit homodimerization and activation (119-121). The vaccinia virus E3L protein like ADAR1 contains a Z-DNA binding domain next to a dsRBD and also blocks IFN induction, PKR, and ADAR1 $(95,121,122)$. Notably, viral ADAR1 inhibition could be a by-product of shielding or sequestering dsRNAs from antiviral PRRs, like PKR, OAS, RIG-I, and MDA5.

ADAR1's dampening effects on antiviral systems and its proviral role during the replication of a wide range of viruses $(81-83,85,87,88)$ suggest that there may also be viruses that have evolved to usurp ADAR1 for their replication. In agreement, a recent study showed that the influenza A virus NS1, and dengue virus NS3 can bind ADAR1 and enhance its editing function, although editing of viral genomes was not investigated (123). As these proteins are also capable of blocking IFN induction, this raises the question whether IFN-inhibition is dependent on ADAR1. The modulation of ADAR1 by viruses underlines the importance of this protein in innate immunity and viral replication, although it must be noted that none of these gene products have been demonstrated to alter A-to-I editing through direct agonism or antagonism of ADAR1 during infection.

\section{ADAR1 AND CANCER}

Recent advances in the field point toward an important role for ADAR1 in tumorigenesis [reviewed in: $(124,125)$ ]. In most tumor types, RNA editing levels are elevated compared to matched normal tissues, suggesting that editing may supplement genomic DNA alterations and drive tumorigenesis (70). Editing in coding regions of certain mRNAs has been associated with oncogenic activity by giving rise to amino acid changes that alter protein properties $(70,124,126-129)$. For example, during esophageal squamous cell carcinoma progression editing of the Antizyme inhibitor 1 mRNA increases, leading to a serine to glycine change that affects cellular polyamine levels. In addition, ADAR1 can also edit microRNAs (miRNAs), which could inhibit their processing or lead to retargeting (130-133). For example, $m i R-200 b$ was found to be overedited in multiple cancer types, leading to retargeting to the tumor suppressor leukemia inhibitory factor receptor. Editing levels of $m i R-200 b$ were found to correlate with poor patient survival. In another study, ADAR1 editing was found to reduce levels of the tumor suppressing let-7 family of miRNAs, leading to enhanced selfrenewal of leukemic stem cells (132). Besides direct effects on miRNA function through editing, ADAR1 has also been shown to interact directly with Dicer to promote processing of siRNAs and miRNAs, RISC loading of miRNAs, and consequently silencing of target RNAs (134). Notably, these effects were independent of ADAR1 editing. These data indicate that loss of ADAR1 could result in dysregulated expression of many genes, which are otherwise silenced by miRNAs. Although ADAR1 is likely to contribute to tumorigenesis by altering gene expression through editing dependent and independent mechanisms, ADAR1 has recently also been shown to contribute to tumorigenesis through its role as regulator of innate immunity.

As reviewed extensively by Parker et al. (135), type I IFNs have important antitumor effects, such as the induction of apoptosis and attraction of infiltrating immune cells. Therefore, malignant cells with dysfunctional IFN responses have a selective advantage. Moreover, the loss of IFN defenses is thought to form the basis for the cancer selectivity of several oncolytic viruses (136). Three recent studies have shown that deleting ADAR1 in tumor cells can induce lethality (137-139). Removal of ADAR1 also rendered these cells more vulnerable to immuno-therapy and overcame resistance to checkpoint blockade, pinpointing ADAR1 as a new immuno-oncology target (138). Interestingly, the lethality of ADAR1 KO tumor cells was rescued by PKR deletion, which is distinct from the embryonic lethality phenotype observed in Adar1-/- mice which was mediated through the MDA5/MAVS pathway $(13,15,16)$. In another study, lethality of A549 ADAR1 KO cells was mediated through the OAS/RNAse L pathway (112). These data indicate that downstream pathways that mediate

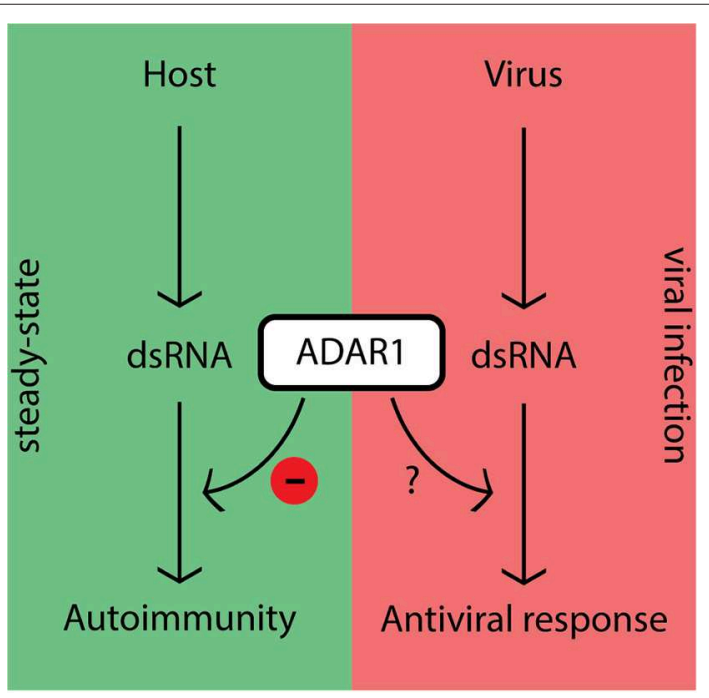

FIGURE 2 | ADAR1's dampening effect on immune activity prevents autoimmunity in steady-state, but should be regulated during viral infection. 
cellular lethality after ADAR1 deletion may depend on the cell type, developmental stage, and/or malignant nature of the cells under investigation. However, the loss of ADAR1, either in normal or malignant cells, will lead to the accumulation of unedited endogenous dsRNAs, which trigger cytoplasmic dsRNA sensors. Malignant cells may have elevated levels of unedited dsRNAs due to the loss of suppressive epigenetic modifications in repeat regions, genomic instability or mitochondrial damage due to oxidative stress (140-142), which would select for cells that have higher editing activities. While the activation of cytoplasmic innate immune sensors is normally deleterious, it may be beneficial in the context of cancer treatment by initiating IFN signaling in the tumor microenvironment. Exploitation of this mechanism through intratumoral ADAR1 inhibition or oncolytic virus therapy using viruses that (naturally) encode ADAR1 inhibitors may be promising candidates for cancer treatment.

\section{ADAR1 REGULATION}

The fact that ADAR1 inhibits canonical antiviral pathways in steady-state raises the question: "How does the host overcome this inhibition during viral infection in order to mount an effective antiviral response?" (Figure 2). Although this question is currently under extensive investigation, several lines of evidence suggest that ADAR1 activity is tightly controlled in the cell. The promoter responsible for p150 expression possesses a consensus interferon-stimulated response element (ISRE) characteristic of ISGs $(33,35,40)$. In steady-state cells generally express low levels of p110 and p150. These levels may not be capable of editing the large amounts of viral dsRNA intermediates generated during replication, which would leave unedited substrates to be recognized by PRRs once the dsRNA levels exceed a certain threshold. However, as transcription is a relatively slow process other, more rapid, regulatory mechanisms are likely to be in place.

Besides regulation at the transcriptional level by IFN, ADAR1 appears to act as a dimer and dimerization can contribute to regulating editing activity and substrate specificity (143, 144). The minimum region required for the dimerization of Drosophila ADAR is the N-terminus including and the first dsRBD (144). Although the exact region required for dimerization of human ADAR is not known yet, the dsRBDs are likely to be involved as these domains often regulate protein dimerization $(78,145)$. Considering that ADAR1 can be modified by SUMO-1 in a region between the Z-DNA and first dsRBD and that this modification decreases editing activity, it is hypothesized that the SUMO modification sterically hinders dimerization, or interferes with substrate binding (146).

Another post-translation modification that affects ADAR1 function is ubiquitination. IFN signaling was shown to promote the Lys-48 mediated ubiquitination and degradation of p110
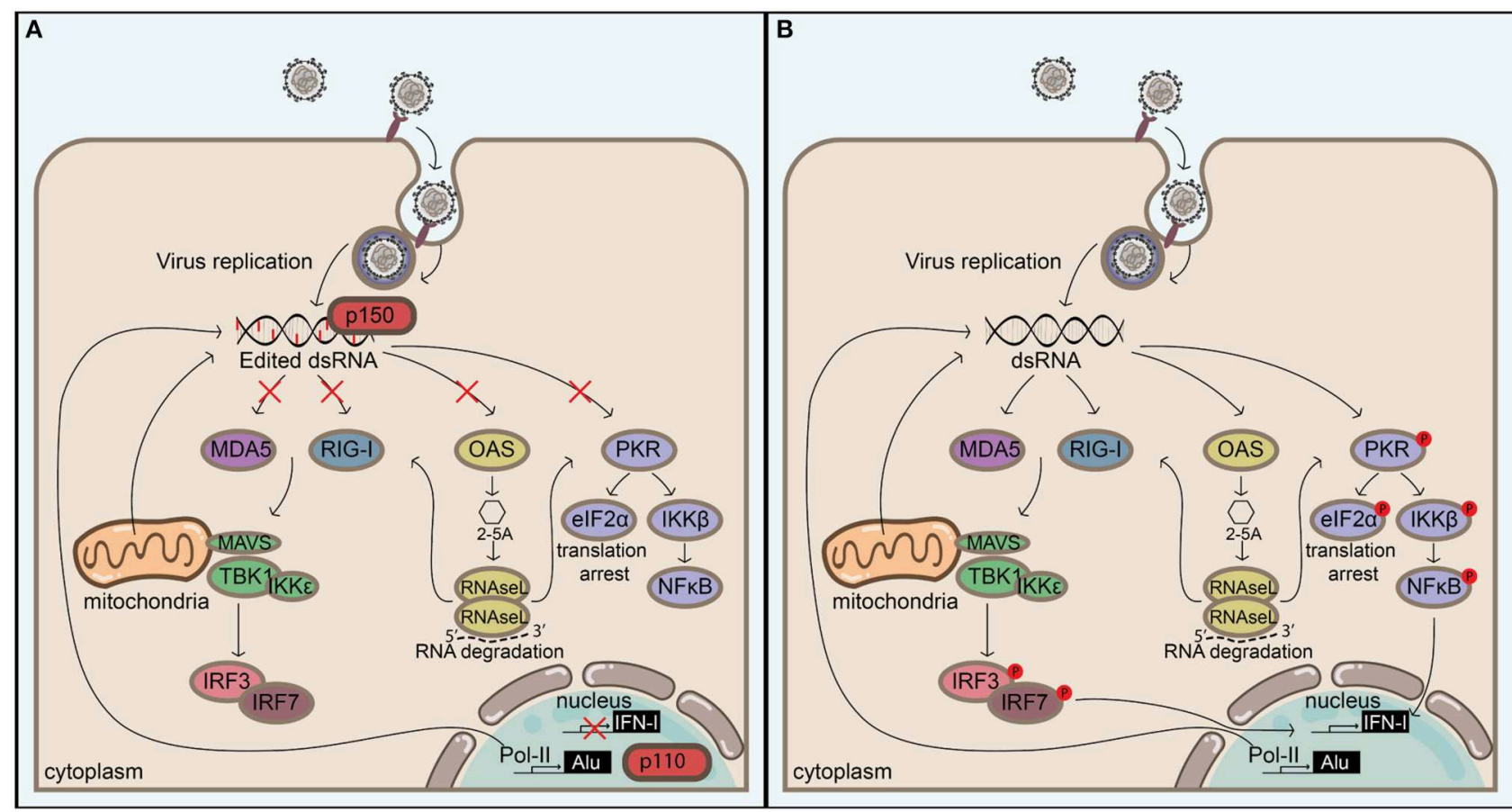

FIGURE 3 | ADAR1 balances self-tolerance and immune activity by modulating canonical antiviral pathways induced by dsRNA. (A) Adenosine to inosine editing or binding of the cytoplasmic ADAR1 isoform p150 or the nuclear p110 to extended dsRNA duplexes prevents their detection by cytoplasmic antiviral signaling pathways, including RIG-I like receptor-, OAS/RNAseL-, and PKR pathways. These dsRNA duplexes can be of viral origin, but in the absence of ADAR1 (B) endogenous dsRNAs - which are likely to originate from inverted Alu repeats or other sources (e.g., mitochondrial dsRNAs) - can also serve as a substrate for antiviral signaling, leading to immune activation, and possibly autoimmunity. Blocking the activation of these pathways prevents IFN-I production, translation arrest, and apoptosis, but this must be tightly regulated in order to not create an environment that favors virus replication. 
(147). Critically, this down-regulation was shown to be required for IFN signaling to execute efficient antiviral activity during VSV infection, suggesting that the cell needs to bypass the constant inhibitory effect of ADAR1 on IFN signaling in order to achieve an effective antiviral response. As p110 is largely absent from the cytoplasm, these data might suggest that newly transcribed unedited endogenous dsRNAs, exported from the nucleus into the cytoplasm, are involved in mounting a robust IFN response. It is tempting to speculate that these endogenous RNAs help stabilize RLR signaling complexes without requiring large amounts of harmful viral dsRNA.

Another mechanism by which ADAR1 could be modulated during viral infection is by regulating the availability of a free inositol pyrophosphate (IP6). IP6 may regulate ADAR1 as it is an essential cofactor for human ADAR2 and has been found buried within the enzyme core of the enzyme (148). In addition, most of the IP6 contact residues are conserved between human ADARs, and yeast ADAT1, a member of a family of related adenosine editing enzymes that act on transfer RNA (tRNA) also relied on IP6 for tRNA editing. Interestingly, a recent study that employed a human genome-wide RNA interference screen identified an essential role for inositol pyrophoshates in the type I IFN response as the activities of the inositol polyphosphate kinases, IPPK, PPIP5K1, and PPIP5K2 (which convert IP5 to IP6 and 1-IP7) were crucial for interferon induction and the control of Sendai and influenza A viruses (149). Whether this is linked to ADAR1 activity remains to be tested.

Altogether, these data indicate that ADAR1 activity can be controlled rapidly through protein-protein interactions, posttranslational modifications, or the availability of cofactors. Downmodulation of ADAR1 activity may be expected early in infection to mount an effective IFN response, but later in infection an increase in ADAR1 activity may be necessary to prevent apoptosis in certain cell types. The discovery of novel mechanisms that regulate ADAR1 activity will be highly interesting for the treatment of viral infections, cancer, and autoimmune diseases.

\section{CONCLUDING REMARKS}

Extended, perfectly matching dsRNA duplexes are unusual in eukaryotic cells and are indicative of viral replication or the expression of endogenous mobile genetic elements. Sensory

\section{REFERENCES}

1. Yoneyama M, Kikuchi M, Natsukawa T, Shinobu N, Imaizumi T, Miyagishi $\mathrm{M}$, et al. The RNA helicase RIG-I has an essential function in doublestranded RNA-induced innate antiviral responses. Nat Immunol. (2004) 5:730-7. doi: 10.1038/ni1087

2. Kato H, Sato S, Yoneyama M, Yamamoto M, Uematsu S, Matsui K, et al. Cell type-specific involvement of RIG-I in antiviral response. Immunity. (2005) 23:19-28. doi: 10.1016/j.immuni.2005.04.010

3. Yoneyama M, Kikuchi M, Matsumoto K, Imaizumi T, Miyagishi M, Taira $\mathrm{K}$, et al. Shared and unique functions of the DExD/H-box helicases RIG-I, MDA5, and LGP2 in antiviral innate immunity. J Immunol. (2005) 175:28518. doi: 10.4049/jimmunol.175.5.2851 systems have evolved to respond to dsRNA. For example, the RLR signaling, PKR, and OAS-RNAse L systems all act as sensors and/or effectors in the response to dsRNA. Findings from studies over the past decade or so indicate that these pathways are all regulated by ADAR1 (Figure 3), which was originally discovered for its ability to unwind dsRNA structures. Although the mechanisms behind ADAR1's regulation of these pathways are currently under extensive investigation, it is likely that there are both editing-dependent and-independent mechanisms. The importance of ADAR1 in maintaining homeostasis is underlined by the severe autoimmune phenotype of AGS patients, which can be recapitulated through homozygous deletion of Adar 1 in mice. In agreement, recent advances confirm that the main function of ADAR1 seems to be to prevent self RNAs from triggering immune responses. The majority of these RNAs is likely to consist of Alu repeats, although the conceptual distinction between self and non-self seems to be complicated by such mobile genetic elements. Intriguingly, these repeats may be beneficial to their host by accelerating host evolution (150), and it seems that expression of ADAR1 allows us to live together with these selfish elements by blocking their intrinsic immunostimulatory molecular patterns. These molecular patterns are also present in viruses, which calls for the need for a tight regulation on A-to-I editing in order to not predispose the host for viral infections. In accordance, dysregulation of ADAR1 may play an important role in viral pathogenesis. In addition, these molecular patterns may be elevated in malignant cells, which may explain why these cells have higher editing activities. This could render malignant cells susceptible to cell death by ADAR1 inhibition and could pinpoint ADAR1 as a new target in immunooncology. Continued investigation of the function and regulation of ADAR1 will help identify mechanisms regulating the balance between immune activity and self-tolerance.

\section{AUTHOR CONTRIBUTIONS}

All authors listed have made a substantial, direct and intellectual contribution to the work, and approved it for publication.

\section{FUNDING}

This work was funded by the Nederlandse Organisatie voor Wetenschappelijk Onderzoek (NWO, grant no. 022.005.032).
4. Fitzgerald KA, McWhirter SM, Faia KL, Rowe DC, Latz E, Golenbock DT, et al. IKKepsilon and TBK1 are essential components of the IRF3 signaling pathway. Nat Immunol. (2003) 4:491-6. doi: 10.1038/ni921

5. Kawai T, Takahashi K, Sato S, Coban C, Kumar H, Kato H, et al. IPS-1, an adaptor triggering RIG-I- and Mda5-mediated type I interferon induction. Nat Immunol. (2005) 6:981-8. doi: 10.1038/ni1243

6. Sato M, Suemori H, Hata N, Asagiri M, Ogasawara K, Nakao K, et al. Distinct and essential roles of transcription factors IRF-3 and IRF-7 in response to viruses for IFN-alpha/beta gene induction. Immunity. (2000) 13:539-48. doi: 10.1016/S1074-7613(00)00053-4

7. Dhir A, Dhir S, Borowski LS, Jimenez L, Teitell M, Rotig A, et al. Mitochondrial double-stranded RNA triggers antiviral signalling in humans. Nature. (2018) 560:238-42. doi: 10.1038/s41586-018-0363-0 
8. Takeuchi O, Akira S. Pattern recognition receptors and inflammation. Cell. (2010) 140:805-20. doi: 10.1016/j.cell.2010.01.022

9. Basilio C, Wahba AJ, Lengyel P, Speyer JF, Ochoa S. Synthetic polynucleotides and the amino acid code. V Proc Natl Acad Sci USA. (1962) 48:613-6. doi: $10.1073 /$ pnas.48.4.613

10. Nishikura K. Functions and regulation of RNA editing by ADAR deaminases. Annu Rev Biochem. (2010) 79:321-49. doi: 10.1146/annurev-biochem-060208-105251

11. Masquida B, Westhof E. On the wobble GoU and related pairs. RNA. (2000) 6:9-15. doi: 10.1017/S1355838200992082

12. Rice GI, Kasher PR, Forte GM, Mannion NM, Greenwood SM, Szynkiewicz $\mathrm{M}$, et al. Mutations in ADAR1 cause Aicardi-Goutieres syndrome associated with a type I interferon signature. Nat Genet. (2012) 44:1243-8. doi: $10.1038 /$ ng.2414

13. Mannion NM, Greenwood SM, Young R, Cox S, Brindle J, Read $\mathrm{D}$, et al. The RNA-editing enzyme ADAR1 controls innate immune responses to RNA. Cell Rep. (2014) 9:1482-94. doi: 10.1016/j.celrep.2014. 10.041

14. Crow YJ, Chase DS, Lowenstein Schmidt J, Szynkiewicz M, Forte GM, Gornall HL, et al. Characterization of human disease phenotypes associated with mutations in TREX1, RNASEH2A, RNASEH2B, RNASEH2C, SAMHD1, ADAR, and IFIH1. Am J Med Genet A. (2015) 167A:296-312. doi: 10.1002/ajmg.a.36887

15. Liddicoat BJ, Piskol R, Chalk AM, Ramaswami G, Higuchi M, Hartner JC, et al. RNA editing by ADAR1 prevents MDA 5 sensing of endogenous dsRNA as nonself. Science. (2015) 349:1115-20. doi: 10.1126/science. aac7049

16. Pestal K, Funk CC, Snyder JM, Price ND, Treuting PM, Stetson DB. Isoforms of RNA-editing enzyme ADAR1 independently control nucleic acid sensor MDA5-driven autoimmunity and multi-organ development. Immunity. (2015) 43:933-44. doi: 10.1016/j.immuni.2015.11.001

17. Samuel CE. Adenosine deaminase acting on RNA (ADAR1), a suppressor of double-stranded RNA-triggered innate immune responses. J Biol Chem. (2019) 294:1710-20. doi: 10.1074/jbc.TM118.004166

18. Bass $\mathrm{BL}$, Weintraub $\mathrm{H}$. A developmentally regulated activity that unwinds RNA duplexes. Cell. (1987) 48:607-13. doi: 10.1016/0092-8674(87)90239-X

19. Rebagliati MR, Melton DA. Antisense RNA injections in fertilized frog eggs reveal an RNA duplex unwinding activity. Cell. (1987) 48:599-605. doi: 10.1016/0092-8674(87)90238-8

20. Bass BL, Weintraub $H$. An unwinding activity that covalently modifies its double-stranded RNA substrate. Cell. (1988) 55:1089-98. doi: 10.1016/0092-8674(88)90253-X

21. Wagner RW, Nishikura K. Cell cycle expression of RNA duplex unwindase activity in mammalian cells. Mol Cell Biol. (1988) 8:770-7. doi: 10.1128/MCB.8.2.770

22. Wagner RW, Smith JE, Cooperman BS, Nishikura K. A double-stranded RNA unwinding activity introduces structural alterations by means of adenosine to inosine conversions in mammalian cells and Xenopus eggs. Proc Natl Acad Sci USA. (1989) 86:2647-51. doi: 10.1073/pnas.86.8.2647

23. Hough RF, Bass BL. Purification of the Xenopus laevis double-stranded RNA adenosine deaminase. J Biol Chem. (1994) 269:9933-9.

24. Kim U, Wang Y, Sanford T, Zeng Y, Nishikura K. Molecular cloning of cDNA for double-stranded RNA adenosine deaminase, a candidate enzyme for nuclear RNA editing. Proc Natl Acad Sci USA. (1994) 91:11457-61. doi: $10.1073 /$ pnas.91.24.11457

25. Bass BL. RNA editing and hypermutation by adenosine deamination. Trends Biochem Sci. (1997) 22:157-62. doi: 10.1016/S0968-0004(97)01035-9

26. Bass BL. RNA editing by adenosine deaminases that act on RNA. Annu Rev Biochem. (2002) 71:817-46. doi: 10.1146/annurev.biochem.71.110601.135501

27. Maas S, Rich A, Nishikura K. A-to-I RNA editing: recent news and residual mysteries. J Biol Chem. (2003) 278:1391-4. doi: 10.1074/jbc.R200025200

28. George CX, Gan Z, Liu Y, Samuel CE. Adenosine deaminases acting on RNA, RNA editing, and interferon action. J Interferon Cytokine Res. (2011) 31:99-117. doi: 10.1089/jir.2010.0097

29. Melcher T, Maas S, Herb A, Sprengel R, Seeburg PH, Higuchi M. A mammalian RNA editing enzyme. Nature. (1996) 379:460-4. doi: $10.1038 / 379460 \mathrm{a} 0$
30. Lonsdale J, Thomas J, Salvatore M, Phillips R, Lo E, Shad S, et al. The genotype-tissue expression (GTEx) project. Nat Genet. (2013) 45:580-5. doi: $10.1038 /$ ng. 2653

31. Melcher T, Maas S, Herb A, Sprengel R, Higuchi M, Seeburg PH. RED2, a brain-specific member of the RNA-specific adenosine deaminase family. $J$ Biol Chem. (1996) 271:31795-8. doi: 10.1074/jbc.271.50.31795

32. Chen CX, Cho DS, Wang Q, Lai F, Carter KC, Nishikura K. A third member of the RNA-specific adenosine deaminase gene family, ADAR3, contains both single- and double-stranded RNA binding domains. RNA. (2000) 6:755-67. doi: 10.1017/S1355838200000170

33. George CX, Samuel CE. Human RNA-specific adenosine deaminase ADAR1 transcripts possess alternative exon 1 structures that initiate from different promoters, one constitutively active and the other interferon inducible. Proc Natl Acad Sci USA. (1999) 96:4621-6. doi: 10.1073/pnas.96.8.4621

34. Poulsen H, Nilsson J, Damgaard CK, Egebjerg J, Kjems J. CRM1 mediates the export of ADAR1 through a nuclear export signal within the Z-DNA binding domain. Mol Cell Biol. (2001) 21:7862-71. doi: 10.1128/MCB.21.22.7862-7871.2001

35. Patterson JB, Samuel CE. Expression and regulation by interferon of a double-stranded-RNA-specific adenosine deaminase from human cells: evidence for two forms of the deaminase. Mol Cell Biol. (1995) 15:5376-88. doi: 10.1128/MCB.15.10.5376

36. Eckmann CR, Neunteufl A, Pfaffstetter L, Jantsch MF. The human but not the Xenopus RNA-editing enzyme ADAR1 has an atypical nuclear localization signal and displays the characteristics of a shuttling protein. Mol Biol Cell. (2001) 12:1911-24. doi: 10.1091/mbc.12.7.1911

37. Strehblow A, Hallegger M, Jantsch MF. Nucleocytoplasmic distribution of human RNA-editing enzyme ADAR1 is modulated by doublestranded RNA-binding domains, a leucine-rich export signal, and a putative dimerization domain. Mol Biol Cell. (2002) 13:3822-35. doi: 10.1091/mbc.e02-03-0161

38. Desterro JM, Keegan LP, Lafarga M, Berciano MT, O'Connell M, CarmoFonseca M. Dynamic association of RNA-editing enzymes with the nucleolus. J Cell Sci. (2003) 116:1805-18. doi: 10.1242/jcs.00371

39. Barraud P, Banerjee S, Mohamed WI, Jantsch MF, Allain FH. A bimodular nuclear localization signal assembled via an extended double-stranded RNAbinding domain acts as an RNA-sensing signal for transportin 1. Proc Natl Acad Sci USA. (2014) 111:E1852-61. doi: 10.1073/pnas.1323698111

40. Patterson JB, Thomis DC, Hans SL, Samuel CE. Mechanism of interferon action: double-stranded RNA-specific adenosine deaminase from human cells is inducible by alpha and gamma interferons. Virology. (1995) 210:50811. doi: 10.1006/viro.1995.1370

41. Wang Q, Khillan J, Gadue P, Nishikura K. Requirement of the RNA editing deaminase ADAR1 gene for embryonic erythropoiesis. Science. (2000) 290:1765-8. doi: 10.1126/science.290.5497.1765

42. Hartner JC, Schmittwolf C, Kispert A, Muller AM, Higuchi M, Seeburg $\mathrm{PH}$. Liver disintegration in the mouse embryo caused by deficiency in the RNA-editing enzyme ADAR1. J Biol Chem. (2004) 279:4894-902. doi: $10.1074 /$ jbc.M311347200

43. Wang Q, Miyakoda M, Yang W, Khillan J, Stachura DL, Weiss MJ, et al. Stress-induced apoptosis associated with null mutation of ADAR1 RNA editing deaminase gene. J Biol Chem. (2004) 279:4952-61. doi: 10.1074/jbc.M310162200

44. Hartner JC, Walkley CR, Lu J, Orkin SH. ADAR1 is essential for the maintenance of hematopoiesis and suppression of interferon signaling. Nat Immunol. (2009) 10:109-15. doi: 10.1038/ni.1680

45. Yang S, Deng P, Zhu Z, Zhu J, Wang G, Zhang L, et al. Adenosine deaminase acting on RNA 1 limits RIG-I RNA detection and suppresses IFN production responding to viral and endogenous RNAs. J Immunol. (2014) 193:3436-45. doi: 10.4049/jimmunol.1401136

46. Wang H, Wang G, Zhang L, Zhang J, Zhang J, Wang Q, et al. ADAR1 suppresses the activation of cytosolic RNA-sensing signaling pathways to protect the liver from ischemia/reperfusion injury. Sci Rep. (2016) 6:20248. doi: $10.1038 /$ srep20248

47. Pujantell M, Riveira-Munoz E, Badia R, Castellvi M, Garcia-Vidal E, Sirera G, et al. RNA editing by ADAR1 regulates innate and antiviral immune functions in primary macrophages. Sci Rep. (2017) 7:13339. doi: 10.1038/s41598-017-13580-0 
48. Aicardi J, Goutieres F. A progressive familial encephalopathy in infancy with calcifications of the basal ganglia and chronic cerebrospinal fluid lymphocytosis. Ann Neurol. (1984) 15:49-54. doi: 10.1002/ana.410150109

49. Lebon P, Badoual J, Ponsot G, Goutieres F, Hemeury-Cukier F, Aicardi J. Intrathecal synthesis of interferon-alpha in infants with progressive familial encephalopathy. J Neurol Sci. (1988) 84:201-8. doi: 10.1016/0022-510X(88)90125-6

50. Bonnemann CG, Meinecke P. Encephalopathy of infancy with intracerebral calcification and chronic spinal fluid lymphocytosis-another case of the Aicardi-Goutieres syndrome. Neuropediatrics. (1992) 23:157-61. doi: $10.1055 / \mathrm{s}-2008-1071333$

51. Rice GI, Forte GM, Szynkiewicz M, Chase DS, Aeby A, Abdel-Hamid MS, et al. Assessment of interferon-related biomarkers in Aicardi-Goutieres syndrome associated with mutations in TREX1, RNASEH2A, RNASEH2B, RNASEH2C, SAMHD1, and ADAR: a case-control study. Lancet Neurol. (2013) 12:1159-69. doi: 10.1016/S1474-4422(13)70258-8

52. Oda H, Nakagawa K, Abe J, Awaya T, Funabiki M, Hijikata A, et al. AicardiGoutieres syndrome is caused by IFIH1 mutations. Am J Hum Genet. (2014) 95:121-5. doi: 10.1016/j.ajhg.2014.06.007

53. Rice GI, Del Toro Duany Y, Jenkinson EM, Forte GM, Anderson BH, Ariaudo G, et al. Gain-of-function mutations in IFIH1 cause a spectrum of human disease phenotypes associated with upregulated type I interferon signaling. Nat Genet. (2014) 46:503-9. doi: 10.1038/ng.2933

54. Ahmad S, Mu X, Yang F, Greenwald E, Park JW, Jacob E, et al. Breaching self-tolerance to alu duplex RNA underlies MDA5-mediated inflammation. Cell. (2018) 172:797-810 e713. doi: 10.1016/j.cell.2017.12.016

55. Lander ES, Linton LM, Birren B, Nusbaum C, Zody MC, Baldwin J, et al. Initial sequencing and analysis of the human genome. Nature. (2001) 409:860-921. doi: 10.1038/35057062

56. Wahlstedt H, Ohman M. Site-selective versus promiscuous A-to-I editing. Wiley Interdiscip Rev RNA. (2011) 2:761-71. doi: 10.1002/wrna.89

57. Athanasiadis A, Rich A, Maas S. Widespread A-to-I RNA editing of Alucontaining mRNAs in the human transcriptome. PLoS Biol. (2004) 2:e391. doi: 10.1371/journal.pbio.0020391

58. Blow M, Futreal PA, Wooster R, Stratton MR. A survey of RNA editing in human brain. Genome Res. (2004) 14:2379-87. doi: 10.1101/gr.2951204

59. Kim DD, Kim TT, Walsh T, Kobayashi Y, Matise TC, Buyske S, et al. Widespread RNA editing of embedded alu elements in the human transcriptome. Genome Res. (2004) 14:1719-25. doi: 10.1101/gr.2855504

60. Levanon EY, Eisenberg E, Yelin R, Nemzer S, Hallegger M, Shemesh R, et al. Systematic identification of abundant A-to-I editing sites in the human transcriptome. Nat Biotechnol. (2004) 22:1001-5. doi: 10.1038/nbt996

61. Li JB, Levanon EY, Yoon JK, Aach J, Xie B, Leproust E, et al. Genome-wide identification of human RNA editing sites by parallel DNA capturing and sequencing. Science. (2009) 324:1210-3. doi: 10.1126/science.1170995

62. Sakurai M, Yano T, Kawabata H, Ueda H, Suzuki T. Inosine cyanoethylation identifies A-to-I RNA editing sites in the human transcriptome. Nat Chem Biol. (2010) 6:733-40. doi: 10.1038/nchembio.434

63. Peng Z, Cheng Y, Tan BC, Kang L, Tian Z, Zhu Y, et al. Comprehensive analysis of RNA-Seq data reveals extensive RNA editing in a human transcriptome. Nat Biotechnol. (2012) 30:253-60. doi: 10.1038/nbt.2122

64. Ramaswami G, Lin W, Piskol R, Tan MH, Davis C, Li JB. Accurate identification of human Alu and non-Alu RNA editing sites. Nat Methods. (2012) 9:579-81. doi: 10.1038/nmeth.1982

65. Ramaswami G, Zhang R, Piskol R, Keegan LP, Deng P, O'Connell MA, et al. Identifying RNA editing sites using RNA sequencing data alone. Nat Methods. (2013) 10:128-32. doi: 10.1038/nmeth.2330

66. Bazak L, Haviv A, Barak M, Jacob-Hirsch J, Deng P, Zhang R, et al. A-to-I RNA editing occurs at over a hundred million genomic sites, located in a majority of human genes. Genome Res. (2014) 24:365-76. doi: 10.1101/gr.164749.113

67. Porath HT, Carmi S, Levanon EY. A genome-wide map of hyperedited RNA reveals numerous new sites. Nat Commun. (2014) 5:4726. doi: $10.1038 /$ ncomms 5726

68. Fumagalli D, Gacquer D, Rothe F, Lefort A, Libert F, Brown D, et al. Principles governing A-to-I RNA editing in the breast cancer transcriptome. Cell Rep. (2015) 13:277-89. doi: 10.1016/j.celrep.2015.09.032
69. Han L, Diao L, Yu S, Xu X, Li J, Zhang R, et al. The genomic landscape and clinical relevance of A-to-I RNA editing in human cancers. Cancer Cell. (2015) 28:515-28. doi: 10.1016/j.ccell.2015.08.013

70. Paz-Yaacov N, Bazak L, Buchumenski I, Porath HT, Danan-Gotthold M, Knisbacher BA, et al. Elevated RNA editing activity is a major contributor to transcriptomic diversity in tumors. Cell Rep. (2015) 13:26776. doi: 10.1016/j.celrep.2015.08.080

71. Chung H, Calis JJA, Wu X, Sun T, Yu Y, Sarbanes SL, et al. Human ADAR1 prevents endogenous RNA from triggering translational shutdown. Cell. (2018) 172:811-24 e814. doi: 10.1016/j.cell.2017.12.038

72. Liddicoat BJ, Chalk AM, Walkley CR. ADAR1, inosine and the immune sensing system: distinguishing self from non-self. Wiley Interdiscip Rev RNA. (2016) 7:157-72. doi: 10.1002/wrna.1322

73. Vitali P, Scadden AD. Double-stranded RNAs containing multiple IU pairs are sufficient to suppress interferon induction and apoptosis. Nat Struct Mol Biol. (2010) 17:1043-50. doi: 10.1038/nsmb.1864

74. Dauber B, Wolff T. Activation of the antiviral kinase PKR and viral countermeasures. Viruses. (2009) 1:523-44. doi: 10.3390/v1030523

75. Ung TL, Cao C, Lu J, Ozato K, Dever TE. Heterologous dimerization domains functionally substitute for the double-stranded RNA binding domains of the kinase PKR. EMBO J. (2001) 20:3728-37. doi: $10.1093 / \mathrm{emboj} / 20.14 .3728$

76. Zhang F, Romano PR, Nagamura-Inoue T, Tian B, Dever TE, Mathews $\mathrm{MB}$, et al. Binding of double-stranded RNA to protein kinase PKR is required for dimerization and promotes critical autophosphorylation events in the activation loop. J Biol Chem. (2001) 276:24946-58. doi: $10.1074 /$ jbc.M102108200

77. Dar AC, Dever TE, Sicheri F. Higher-order substrate recognition of eIF2alpha by the RNA-dependent protein kinase PKR. Cell. (2005) 122:887900. doi: 10.1016/j.cell.2005.06.044

78. Dey M, Cao C, Dar AC, Tamura T, Ozato K, Sicheri F, et al. Mechanistic link between PKR dimerization, autophosphorylation, and eIF2alpha substrate recognition. Cell. (2005) 122:901-13. doi: 10.1016/j.cell.2005.06.041

79. Farrell PJ, Sen GC, Dubois MF, Ratner L, Slattery E, Lengyel P. Interferon action: two distinct pathways for inhibition of protein synthesis by double-stranded RNA. Proc Natl Acad Sci USA. (1978) 75:5893-7. doi: $10.1073 /$ pnas.75.12.5893

80. Levin D, London IM. Regulation of protein synthesis: activation by double-stranded RNA of a protein kinase that phosphorylates eukaryotic initiation factor 2. Proc Natl Acad Sci USA. (1978) 75:1121-5. doi: 10.1073/pnas.75.3.1121

81. Nie Y, Hammond GL, Yang JH. Double-stranded RNA deaminase ADAR1 increases host susceptibility to virus infection. J Virol. (2007) 81:917-23. doi: 10.1128/JVI.01527-06

82. Clerzius G, Gelinas JF, Daher A, Bonnet M, Meurs EF, Gatignol A. ADAR1 interacts with PKR during human immunodeficiency virus infection of lymphocytes and contributes to viral replication. J Virol. (2009) 83:10119-28. doi: 10.1128/JVI.02457-08

83. Toth AM, Li Z, Cattaneo R, Samuel CE. RNA-specific adenosine deaminase ADAR1 suppresses measles virus-induced apoptosis and activation of protein kinase PKR. J Biol Chem. (2009) 284:29350-6. doi: $10.1074 /$ jbc.M109.045146

84. Wang Y, Samuel CE. Adenosine deaminase ADAR1 increases gene expression at the translational level by decreasing protein kinase PKRdependent eIF-2alpha phosphorylation. J Mol Biol. (2009) 393:777-87. doi: 10.1016/j.jmb.2009.08.070

85. Li Z, Wolff KC, Samuel CE. RNA adenosine deaminase ADAR1 deficiency leads to increased activation of protein kinase PKR and reduced vesicular stomatitis virus growth following interferon treatment. Virology. (2010) 396:316-22. doi: 10.1016/j.virol.2009.10.026

86. John L, Samuel CE. Induction of stress granules by interferon and downregulation by the cellular RNA adenosine deaminase ADAR1. Virology. (2014). 454-5:299-310. doi: 10.1016/j.virol.2014.02.025

87. Phuphuakrat A, Kraiwong R, Boonarkart C, Lauhakirti D, Lee TH, Auewarakul P. Double-stranded RNA adenosine deaminases enhance expression of human immunodeficiency virus type 1 proteins. J Virol. (2008) 82:10864-72. doi: 10.1128/JVI.00238-08 
88. Doria M, Neri F, Gallo A, Farace MG, Michienzi A. Editing of HIV-1 RNA by the double-stranded RNA deaminase ADAR1 stimulates viral infection. Nucleic Acids Res. (2009) 37:5848-58. doi: 10.1093/nar/gkp604

89. Okonski KM, Samuel CE. Stress granule formation induced by measles virus is protein kinase PKR dependent and impaired by RNA adenosine deaminase ADAR1. J Virol. (2013) 87:756-66. doi: 10.1128/JVI.02270-12

90. Ng CS, Jogi M, Yoo JS, Onomoto K, Koike S, Iwasaki T, et al. Encephalomyocarditis virus disrupts stress granules, the critical platform for triggering antiviral innate immune responses. J Virol. (2013) 87:9511-22. doi: 10.1128/JVI.03248-12

91. Pfaller CK, Li Z, George CX, Samuel CE. Protein kinase PKR and RNA adenosine deaminase ADAR1: new roles for old players as modulators of the interferon response. Curr Opin Immunol. (2011) 23:573-82. doi: 10.1016/j.coi.2011.08.009

92. Zamanian-Daryoush M, Mogensen TH, DiDonato JA, Williams BR. NFkappaB activation by double-stranded-RNA-activated protein kinase (PKR) is mediated through NF-kappaB-inducing kinase and IkappaB kinase. $\mathrm{Mol}$ Cell Biol. (2000) 20:1278-90. doi: 10.1128/MCB.20.4.1278-1290.2000

93. Gil J, Garcia MA, Gomez-Puertas P, Guerra S, Rullas J, Nakano H, et al. TRAF family proteins link PKR with NF-kappa B activation. Mol Cell Biol. (2004) 24:4502-12. doi: 10.1128/MCB.24.10.4502-4512.2004

94. Yang YL, Reis LF, Pavlovic J, Aguzzi A, Schafer R, Kumar A, et al. Deficient signaling in mice devoid of double-stranded RNA-dependent protein kinase. EMBO J. (1995) 14:6095-106. doi: 10.1002/j.1460-2075.1995.tb00300.x

95. Smith EJ, Marie I, Prakash A, Garcia-Sastre A, Levy DE. IRF3 and IRF7 phosphorylation in virus-infected cells does not require doublestranded RNA-dependent protein kinase R or Ikappa B kinase but is blocked by Vaccinia virus E3L protein. J Biol Chem. (2001) 276:8951-7. doi: 10.1074/jbc.M008717200

96. Diebold SS, Montoya M, Unger H, Alexopoulou L, Roy P, Haswell LE, et al. Viral infection switches non-plasmacytoid dendritic cells into high interferon producers. Nature. (2003) 424:324-8. doi: 10.1038/nature01783

97. McAllister CS, Samuel CE. The RNA-activated protein kinase enhances the induction of interferon-beta and apoptosis mediated by cytoplasmic RNA sensors. J Biol Chem. (2009) 284:1644-51. doi: 10.1074/jbc.M807888200

98. Carpentier PA, Williams BR, Miller SD. Distinct roles of protein kinase R and toll-like receptor 3 in the activation of astrocytes by viral stimuli. Glia. (2007) 55:239-52. doi: 10.1002/glia.20450

99. Gilfoy FD, Mason PW. West Nile virus-induced interferon production is mediated by the double-stranded RNA-dependent protein kinase PKR. $J$ Virol. (2007) 81:11148-58. doi: 10.1128/JVI.00446-07

100. Barry G, Breakwell L, Fragkoudis R, Attarzadeh-Yazdi G, Rodriguez-Andres J, Kohl A, et al. PKR acts early in infection to suppress Semliki Forest virus production and strongly enhances the type I interferon response. J Gen Virol. (2009) 90:1382-91. doi: 10.1099/vir.0.007336-0

101. McAllister CS, Toth AM, Zhang P, Devaux P, Cattaneo R, Samuel CE. Mechanisms of protein kinase PKR-mediated amplification of beta interferon induction by C protein-deficient measles virus. J Virol. (2010) 84:380-6. doi: 10.1128/JVI.02630-08

102. Schulz O, Pichlmair A, Rehwinkel J, Rogers NC, Scheuner D, Kato H, et al. Protein kinase $\mathrm{R}$ contributes to immunity against specific viruses by regulating interferon mRNA integrity. Cell Host Microbe. (2010) 7:354-61. doi: 10.1016/j.chom.2010.04.007

103. Pham AM, Santa Maria FG, Lahiri T, Friedman E, Marie IJ, Levy DE. PKR Transduces MDA5-dependent signals for Type I IFN induction. PLoS Pathog. (2016) 12:e1005489. doi: 10.1371/journal.ppat.1005489

104. Dong B, Silverman RH. 2-5A-dependent RNase molecules dimerize during activation by 2-5A. J Biol Chem. (1995) 270:4133-7. doi: $10.1074 /$ jbc. 270.8 .4133

105. Wreschner DH, McCauley JW, Skehel JJ, Kerr IM. Interferon actionsequence specificity of the $\operatorname{ppp}(\mathrm{A} 2$ 'p)nA-dependent ribonuclease. Nature. (1981) 289:414-7. doi: 10.1038/289414a0

106. Wreschner DH, James TC, Silverman RH, Kerr IM. Ribosomal RNA cleavage, nuclease activation and 2-5A(ppp(A2'p)nA) in interferon-treated cells. Nucleic Acids Res. (1981) 9:1571-81. doi: 10.1093/nar/9.7.1571

107. Chakrabarti A, Ghosh PK, Banerjee S, Gaughan C, Silverman RH. RNase L triggers autophagy in response to viral infections. J Virol. (2012) 86:1131121. doi: $10.1128 /$ JVI.00270-12
108. Siddiqui MA, Malathi K. RNase L induces autophagy via c-Jun N-terminal kinase and double-stranded RNA-dependent protein kinase signaling pathways. J Biol Chem. (2012) 287:43651-64. doi: 10.1074/jbc.M112.399964

109. Castelli JC, Hassel BA, Wood KA, Li XL, Amemiya K, Dalakas MC, et al. A study of the interferon antiviral mechanism: apoptosis activation by the 2-5A system. J Exp Med. (1997) 186:967-72. doi: 10.1084/jem.186.6.967

110. Zhou A, Paranjape J, Brown TL, Nie H, Naik S, Dong B, et al. Interferon action and apoptosis are defective in mice devoid of 2'5'-oligoadenylate-dependent RNase L. EMBO J. (1997) 16:6355-63. doi: 10.1093/emboj/16.21.6355

111. Castelli J, Wood KA, Youle RJ. The 2-5A system in viral infection and apoptosis. Biomed Pharmacother. (1998) 52:386-90. doi: 10.1016/S0753-3322(99)80006-7

112. Li Y, Banerjee S, Goldstein SA, Dong B, Gaughan C, Rath S, et al. Ribonuclease L mediates the cell-lethal phenotype of double-stranded RNA editing enzyme ADAR1 deficiency in a human cell line. Elife. (2017) 6:e25687. doi: 10.7554/eLife.25687

113. Samuel CE. Adenosine deaminases acting on RNA (ADARs) are both antiviral and proviral. Virology. (2011) 411:180-93. doi: 10.1016/j.virol.2010.12.004

114. Ohara PJ, Nichol ST, Horodyski FM, Holland JJ. Vesicular stomatitisvirus defective interfering particles can contain extensive genomic sequence rearrangements and base substitutions. Cell. (1984) 36:915-24. doi: 10.1016/0092-8674(84)90041-2

115. Cattaneo R, Schmid A, Eschle D, Baczko K, Termeulen V, Billeter MA. Biased hypermutation and other genetic changes in defective measles viruses in human-brain infections. Cell. (1988) 55:255-65. doi: 10.1016/0092-8674(88)90048-7

116. van den Hoogen BG, van Boheemen S, de Rijck J, van Nieuwkoop S, Smith DJ, Laksono B, et al. Excessive production and extreme editing of human metapneumovirus defective interfering RNA is associated with type I IFN induction. J Gen Virol. (2014) 95:1625-33. doi: 10.1099/vir.0.066100-0

117. Kitajewski J, Schneider RJ, Safer B, Munemitsu SM, Samuel CE, Thimmappaya B, et al. Adenovirus VAI RNA antagonizes the antiviral action of interferon by preventing activation of the interferon-induced eIF-2 alpha kinase. Cell. (1986) 45:195-200. doi: 10.1016/0092-8674(86)90383-1

118. Mori K, Juttermann R, Wienhues U, Kobayashi K, Yagi M, Sugimoto $\mathrm{T}$, et al. Anti-interferon activity of adenovirus-2-encoded VAI and VAII RNAs in translation in cultured human cells. Virus Res. (1996) 42:53-63. doi: 10.1016/0168-1702(95)01309-1

119. Lei M, Liu Y, Samuel CE. Adenovirus VAI RNA antagonizes the RNA-editing activity of the ADAR adenosine deaminase. Virology. (1998) 245:188-96. doi: 10.1006/viro.1998.9162

120. Katze MG, DeCorato D, Safer B, Galabru J, Hovanessian AG. Adenovirus VAI RNA complexes with the $68000 \mathrm{Mr}$ protein kinase to regulate its autophosphorylation and activity. EMBO J. (1987) 6:689-97. doi: 10.1002/j.1460-2075.1987.tb04809.x

121. Liu Y, Wolff KC, Jacobs BL, Samuel CE. Vaccinia virus E3L interferon resistance protein inhibits the interferon-induced adenosine deaminase A-to-I editing activity. Virology. (2001) 289:378-87. doi: 10.1006/viro.2001.1154

122. Chang HW, Watson JC, Jacobs BL. The E3L gene of vaccinia virus encodes an inhibitor of the interferon-induced, double-stranded RNAdependent protein kinase. Proc Natl Acad Sci USA. (1992) 89:4825-9. doi: $10.1073 /$ pnas.89.11.4825

123. de Chassey B, Aublin-Gex A, Ruggieri A, Meyniel-Schicklin L, Pradezynski F, Davoust N, et al. The interactomes of influenza virus NS1 and NS2 proteins identify new host factors and provide insights for ADAR1 playing a supportive role in virus replication. PLoS Pathog. (2013) 9:e1003440. doi: 10.1371/journal.ppat.1003440

124. Fritzell K, Xu LD, Lagergren J, Ohman M. ADARs and editing: the role of A-to-I RNA modification in cancer progression. Semin Cell Dev Biol. (2018) 79:123-30. doi: 10.1016/j.semcdb.2017.11.018

125. Bhate A, Sun T, Li JB. ADAR1: a new target for immuno-oncology therapy. Mol Cell. (2019) 73:866-8. doi: 10.1016/j.molcel.2019.02.021

126. Chen L, Li Y, Lin CH, Chan TH, Chow RK, Song Y, et al. Recoding RNA editing of AZIN1 predisposes to hepatocellular carcinoma. Nat Med. (2013) 19:209-16. doi: 10.1038/nm.3043 
127. Qin YR, Qiao JJ, Chan TH, Zhu YH, Li FF, Liu H, et al. Adenosine-to-inosine RNA editing mediated by ADARs in esophageal squamous cell carcinoma. Cancer Res. (2014) 74:840-51. doi: 10.1158/0008-5472.CAN-13-2545

128. Hu X, Wan S, Ou Y, Zhou B, Zhu J, Yi X, et al. RNA overediting of BLCAP contributes to hepatocarcinogenesis identified by wholegenome and transcriptome sequencing. Cancer Lett. (2015) 357:510-9. doi: 10.1016/j.canlet.2014.12.006

129. Chen Y, Wang H, Lin W, Shuai P. ADAR1 overexpression is associated with cervical cancer progression and angiogenesis. Diagn Pathol. (2017) 12:12. doi: 10.1186/s13000-017-0600-0

130. Yang WD, Chendrimada TP, Wang QD, Higuchi M, Seeburg PH, Shiekhattar $\mathrm{R}$, et al. Modulation of microRNA processing and expression through RNA editing by ADAR deaminases. Nat Struct Mol Biol. (2006) 13:13-21. doi: $10.1038 / \mathrm{nsmb} 1041$

131. Kawahara Y, Megraw M, Kreider E, Iizasa H, Valente L, Hatzigeorgiou AG, et al. Frequency and fate of microRNA editing in human brain. Nucleic Acids Res. (2008) 36:5270-80. doi: 10.1093/nar/gkn479

132. Zipeto MA, Court AC, Sadarangani A, Delos Santos NP, Balaian L, Chun HJ, et al. ADAR1 activation drives leukemia stem cell selfrenewal by impairing Let-7 biogenesis. Cell Stem Cell. (2016) 19:177-91. doi: 10.1016/j.stem.2016.05.004

133. Wang Y, Xu X, Yu S, Jeong KJ, Zhou Z, Han L, et al. Systematic characterization of A-to-I RNA editing hotspots in microRNAs across human cancers. Genome Res. (2017) 27:1112-25. doi: 10.1101/gr.219741.116

134. Ota H, Sakurai M, Gupta R, Valente L, Wulff BE, Ariyoshi K, et al. ADAR1 forms a complex with Dicer to promote microRNA processing and RNA-induced gene silencing. Cell. (2013) 153:575-89. doi: 10.1016/j.cell.2013.03.024

135. Parker BS, Rautela J, Hertzog PJ. Antitumour actions of interferons: implications for cancer therapy. Nat Rev Cancer. (2016) 16:131-44. doi: $10.1038 /$ nrc. 2016.14

136. Matveeva OV, Chumakov PM. Defects in interferon pathways as potential biomarkers of sensitivity to oncolytic viruses. Rev Med Virol. (2018) 28:e2008. doi: $10.1002 / \mathrm{rmv} .2008$

137. Gannon HS, Zou T, Kiessling MK, Gao GF, Cai D, Choi PS, et al. Identification of ADAR1 adenosine deaminase dependency in a subset of cancer cells. Nat Commun. (2018) 9:5450. doi: 10.1038/s41467-018-07824-4

138. Ishizuka JJ, Manguso RT, Cheruiyot CK, Bi K, Panda A, Iracheta-Vellve A, et al. Loss of ADAR1 in tumours overcomes resistance to immune checkpoint blockade. Nature. (2019) 565:43-8. doi: 10.1038/s41586-018-0768-9

139. Liu H, Golji J, Brodeur LK, Chung FS, Chen JT, deBeaumont RS, et al. Tumor-derived IFN triggers chronic pathway agonism and sensitivity to ADAR loss. Nat Med. (2019) 25:95-102. doi: 10.1038/s41591-018-0302-5

140. Carone DM, Lawrence JB. Heterochromatin instability in cancer: from the Barr body to satellites and the nuclear periphery. Semin Cancer Biol. (2013) 23:99-108. doi: 10.1016/j.semcancer.2012.06.008
141. Levine AJ, Ting DT, Greenbaum BD. P53 and the defenses against genome instability caused by transposons and repetitive elements. Bioessays. (2016) 38:508-13. doi: 10.1002/bies.201600031

142. Wylie A, Jones AE, D'Brot A, Lu WJ, Kurtz P, Moran JV, et al. p53 genes function to restrain mobile elements. Genes Dev. (2016) 30:64-77. doi: $10.1101 / \operatorname{gad} .266098 .115$

143. Cho DS, Yang W, Lee JT, Shiekhattar R, Murray JM, Nishikura K. Requirement of dimerization for RNA editing activity of adenosine deaminases acting on RNA. J Biol Chem. (2003) 278:17093-102. doi: $10.1074 /$ jbc.M213127200

144. Gallo A, Keegan LP, Ring GM, O'Connell MA. An ADAR that edits transcripts encoding ion channel subunits functions as a dimer. EMBO J. (2003) 22:3421-30. doi: 10.1093/emboj/cdg327

145. Doyle M, Jantsch MF. New and old roles of the doublestranded RNA-binding domain. J Struct Biol. (2002) 140:147-53. doi: 10.1016/S1047-8477(02)00544-0

146. Desterro JM, Keegan LP, Jaffray E, Hay RT, O’Connell MA, Carmo-Fonseca M. SUMO-1 modification alters ADAR1 editing activity. Mol Biol Cell. (2005) 16:5115-26. doi: 10.1091/mbc.e05-06-0536

147. Li L, Qian G, Zuo Y, Yuan Y, Cheng Q, Guo T, et al. Ubiquitin-dependent turnover of adenosine deaminase acting on RNA 1 (ADAR1) is required for efficient antiviral activity of type I interferon. J Biol Chem. (2016) 291:24974-85. doi: 10.1074/jbc.M116.737098

148. Macbeth MR, Schubert HL, Vandemark AP, Lingam AT, Hill CP, Bass $\mathrm{BL}$. Inositol hexakisphosphate is bound in the ADAR2 core and required for RNA editing. Science. (2005) 309:1534-9. doi: 10.1126/science.11 13150

149. Pulloor NK, Nair S, Kostic AD, Bist P, Weaver JD, Riley AM, et al. Human genome-wide RNAi screen identifies an essential role for inositol pyrophosphates in type-I interferon response. Plos Pathog. (2014) 10:e1003981. doi: 10.1371/journal.ppat.1003981

150. Knisbacher BA, Levanon EY. DNA and RNA editing of retrotransposons accelerate mammalian genome evolution. Ann N Y Acad Sci. (2015) 1341:115-25. doi: 10.1111/nyas.12713

Conflict of Interest Statement: The authors declare that the research was conducted in the absence of any commercial or financial relationships that could be construed as a potential conflict of interest.

Copyright (c) 2019 Lamers, van den Hoogen and Haagmans. This is an open-access article distributed under the terms of the Creative Commons Attribution License (CC $B Y)$. The use, distribution or reproduction in other forums is permitted, provided the original author(s) and the copyright owner(s) are credited and that the original publication in this journal is cited, in accordance with accepted academic practice. No use, distribution or reproduction is permitted which does not comply with these terms. 